\title{
Small RNA functions in carbon metabolism and virulence of enteric pathogens
}

\author{
Kai Papenfort ${ }^{1 *}$ and Jörg Vogel ${ }^{2}$ \\ 1 Department of Molecular Biology, Princeton University, Princeton, NJ, USA \\ ${ }^{2}$ RNA Biology Group, Institute for Molecular Infection Biology, University of Würzburg, Würzburg, Germany
}

\section{Edited by:}

Thomas Dandekar, University of

Würzburg, Germany

Reviewed by:

Michael Shapira, University of

California, Berkeley, USA

Petra Dersch, Helmholtz Center for

Infection Research, Germany

*Correspondence:

Kai Papenfort, Department of Molecular Biology, Princeton

University, Washington Road,

Princeton, NJ 08544, USA

e-mail:kaip@princeton.edu
Enteric pathogens often cycle between virulent and saprophytic lifestyles. To endure these frequent changes in nutrient availability and composition bacteria possess an arsenal of regulatory and metabolic genes allowing rapid adaptation and high flexibility. While numerous proteins have been characterized with regard to metabolic control in pathogenic bacteria, small non-coding RNAs have emerged as additional regulators of metabolism. Recent advances in sequencing technology have vastly increased the number of candidate regulatory RNAs and several of them have been found to act at the interface of bacterial metabolism and virulence factor expression. Importantly, studying these riboregulators has not only provided insight into their metabolic control functions but also revealed new mechanisms of post-transcriptional gene control. This review will focus on the recent advances in this area of host-microbe interaction and discuss how regulatory small RNAs may help coordinate metabolism and virulence of enteric pathogens.

Keywords: sRNA, carbon metabolism, Hfq, CsrA, virulence

\section{INTRODUCTION}

Bacteria colonize almost every niche on earth. Accordingly, they have developed complex regulatory systems to respond to their environment. In particular, the right choice of nutrients is crucial to thrive in conditions of stress or competition. Pathogenic bacteria are no different in this respect. At the very heart of most infections, the host presents an exquisite source of nutrients for the pathogen. However, the immune response of the host can create a hostile environment demanding precise coordination of stress-related and metabolic genes.

Transcription factors have long been known to link metabolic pathways and virulence gene expression. The highly conserved cAMP receptor protein (CRP) transcription factor, for example, coordinates the uptake and utilization of alternative carbon sources in a process termed carbon catabolite repression (CCR) (Gorke and Stulke, 2008). Mutations in CCR components often have drastic consequences for virulence gene expression (Poncet et al., 2009) and loss of CRP activity, either by mutation or low intracellular cAMP levels, strongly reduces the virulence of Salmonella enterica (Curtiss and Kelly, 1987; Teplitski et al., 2006), Vibrio cholerae (Skorupski and Taylor, 1997), and Yersinia species (Petersen and Young, 2002; Kim et al., 2007).

Besides protein-dependent transcriptional control, RNAcontrolled mechanisms have turned out to play important roles in regulating virulence genes (Papenfort and Vogel, 2010). Regulatory RNAs operate at all layers of gene expression, ranging from transcription initiation to translation control and protein activity (Waters and Storz, 2009). The majority of the regulatory RNAs characterized to date act by base-pairing with target mRNAs and are commonly referred to as small regulatory RNAs (sRNAs). This group can be further divided into sRNAs encoded on the opposite strand of the regulated RNA (cis-encoded) and those that are transcribed distantly from their targets (transencoded). These sRNAs have been documented to regulate numerous important processes in bacterial pathogens including outer membrane homeostasis (Papenfort et al., 2006, 2010; Song et al., 2008; Corcoran et al., 2012; Fröhlich et al., 2012), quorum sensing (Lenz et al., 2004; Shao et al., 2013), iron homeostasis (Murphy and Payne, 2007), biofilm formation (Monteiro et al., 2012; Zhao et al., 2013), host-cell contact (Heroven et al., 2008; Sterzenbach et al., 2013; Gruber and Sperandio, 2014), and amino-acid metabolism (Sharma et al., 2011).

Other classes of riboregulators are riboswitches (Serganov and Nudler, 2013) or RNA thermometers (Kortmann and Narberhaus, 2012). Both describe RNA elements typically found in the $5^{\prime}$ UTR (untranslated region) of mRNAs regulating gene expression via structural rearrangements of the RNA. Whereas riboswitches respond to varying availability of metabolites or metals in the cell, RNA thermometers function by sensing changes in temperature. Riboswitches may also produce small RNAs (Vogel et al., 2003) and act as trans-acting regulators on mRNAs (Loh et al., 2009). For many pathogenic bacteria, host body temperature is a central signal activating virulence gene expression. RNA thermometers have been shown to contribute to this regulation in enteric bacteria such as Yersinia pseudotuberculosis and Listeria monocytogenes (Johansson et al., 2002; Bohme et al., 2012), as well as the non-enteric human pathogen Neisseria meningitidis (Loh et al., 2013).

Due to the relatively small size of their genes or simply because of incomplete genome annotations riboregulators were often overlooked in traditional genetic screens for virulence determinants. In addition, the fact that most regulatory RNAs may act to 
fine-tune processes and so give milder phenotypes when mutated than regulatory proteins has also disfavored their identification in virulence screens. However, the recent advent of next-generation sequencing (NGS) techniques has begun to remedy some of these limitations: NGS can provide global maps of RNA expression at nucleotide resolution for any bacterial pathogen of interest, and some of the newly identified sRNAs have already been documented to contribute to microbial virulence (Caldelari et al., 2013).

Evidence for regulatory RNAs being important for the control of virulence and metabolism has also come from the loss-offunction phenotypes of two proteins, Hfq (a.k.a. HF-I protein) and CsrA (carbon storage regulator A). The RNA chaperone, $\mathrm{Hfq}$, is required for virulence in diverse bacterial pathogens and $h f q$ mutants usually display pleiotropic defects such as reduced growth rates, altered metabolic profiles and changes in virulence gene expression (Chao and Vogel, 2010; Sobrero and Valverde, 2012). At the mechanistic level, Hfq is known to serve as a "molecular matchmaker" by facilitating base-pairing of sRNAs and target mRNAs but it also protect sRNAs from degradation by cellular ribonucleases (Vogel and Luisi, 2011). In the laboratory, Hfq has proven as a useful tool to precipitate bona-fide sRNAs (Chao et al., 2012 and references therein) and therefore frequently served as starting point for the functional characterization of sRNA regulators.

Likewise, the RNA-binding protein CsrA (a.k.a. RsmA in some organisms) is required for virulence of many pathogens (Lucchetti-Miganeh et al., 2008). Originally described as a pleiotropic regulator of glycogen biosynthesis in Escherichia coli (Romeo et al., 1993), CsrA homologs have now been annotated in more than 1500 bacterial species (Finn et al., 2014). Binding of CsrA occurs at GGA-rich elements in the mRNA and commonly results in reduced ribosome association and subsequent mRNA decay (Romeo et al., 2013), though CsrA-mediated gene activation has also been reported (Yakhnin et al., 2013). The key regulators of CsrA activity are CsrB-like sRNAs which act as decoys of the protein. These sRNAs, of which many bacteria encode more than one copy, carry multiple high-affinity sites containing the GGA motif and thereby titrate CsrA away from its target mRNAs (Babitzke and Romeo, 2007).

Recent global studies of other gastrointinal pathogens such as Helicobacter pylori (Sharma et al., 2010), Campylobacter jejunii (Dugar et al., 2013), and Clostridium difficile (Soutourina et al., 2013) have suggested a wealth of potential RNA regulators in these organisms, but if and how these are involved in metabolic processes and infection is mostly unclear. Therefore, in this review we concentrated on the functions of established sRNAs in carbon metabolism and virulence of enteric pathogens and, where applicable, outlined the underlying mechanisms of regulation.

\section{GLUCOSE HOMEOSTASIS THROUGH SgrS}

The facultative intracellular pathogen $S$. enterica serovar Typhimurium is probably one of the best understood bacteria when it comes to metabolic profiling during infection (Dandekar et al., 2012). Transcriptome analyses of intracellular Salmonella suggested a preference for glucose, glucose-6-phosphate (G-6-P), and gluconate as primary carbon sources during infection
(Hautefort et al., 2008); the preference for glucose (though not G-6-P) during intracellular growth was also supported by isotopologue profiling experiments (Gotz et al., 2010). In agreement with these observed preferences, glucose and glycolysis are essential for the virulence of Salmonella (Bowden et al., 2009).

Glucose uptake and catabolism are strictly controlled, and Salmonella shares many of the underlying regulatory mechanisms with its close relative, E. coli. The transport of glucose across the bacterial membrane is achieved by so-called phosphotransferase systems (PTS) (Jahreis et al., 2008). Gram-negative model bacteria encode a plethora of PTS with varying substrate specificities (Deutscher et al., 2006). For glucose, the translocation process generates G-6-P (Figure 1) which, once in the cytosol, can enter several metabolic pathways including glycolysis or the pentose-phosphate pathway.

Phosphosugars such as G-6-P are a double-edged sword, though. On the one hand, they serve as a primary energy source for generating ATP and NADH via glycolysis. On the other hand, high levels of phosphorylated sugars can impair growth (Irani and Maitra, 1977; Kadner et al., 1992) and may cause DNA damage (Lee and Cerami, 1987). Importantly, many non-metabolizable carbohydrates are invariably imported and phosphorylated by Crr and PtsG, the major proteins for glucose uptake in E. coli and Salmonella. The accumulation of intracellular G-6-P or other phosphorylated sugars is often referred to as phosphosugar stress and has been observed in many Gram negative bacteria (Bobrovskyy and Vanderpool, 2013). Not surprisingly, intracellular glucose levels are strictly controlled and glucose homeostasis is subject to complex transcriptional and post-transcriptional control. Six transcriptional regulators, including the two alternative sigma-factors $\sigma^{\mathrm{S}}$ and $\sigma^{\mathrm{H}}$, control the $p t s G$ gene in E. coli (Jahreis et al., 2008). Furthermore, the $p t s G$ mRNA is destabilized in response to high intracellular G-6-P levels (Kimata et al., 2001), an effect which could be attributed to the activity of a phosphosugar stress-induced sRNA, SgrS (Vanderpool and Gottesman, 2004). Upon activation by the SgrR transcriptional regulator (Vanderpool and Gottesman, 2004, 2007), SgrS base-pairs with the ribosome binding site (RBS) of the $p t s G$ mRNA to inhibit translation initiation. Thereby SgrS reduces de novo production of PtsG protein and limits glucose import and intracellular G-6-P levels (Vanderpool and Gottesman, 2004) (Figures 1, 2).

SgrS has many characteristics of an Hfq-dependent sRNA: it co-immunoprecipitates with Hfq (Zhang et al., 2003) and mutation of the $h f q$ gene impairs the intracellular stability of SgrS and its ability to repress the ptsG mRNA (Kawamoto et al., 2006). Recent work showed that Hfq binds at the Rho-independent transcriptional terminator hairpin at the $3^{\prime}$ end of SgrS (Otaka et al., 2011; Ishikawa et al., 2012). SgrS has also been a model sRNA in establishing general mechanisms of sRNA activity in bacteria. For example, the Aiba group showed that successful repression of $p t s G$ by SgrS required a very short seed pairing, involving as few as six essential base-pairs (Kawamoto et al., 2006; Maki et al., 2010); that regulation may occur at the inner membrane (Kawamoto et al., 2005); and crucially involves RNase E (Morita et al., 2005). Interestingly, although SgrS induces ptsG mRNA decay (Morita et al., 2005), RNA duplex-formation alone suffices for translational repression (Morita et al., 2006). 


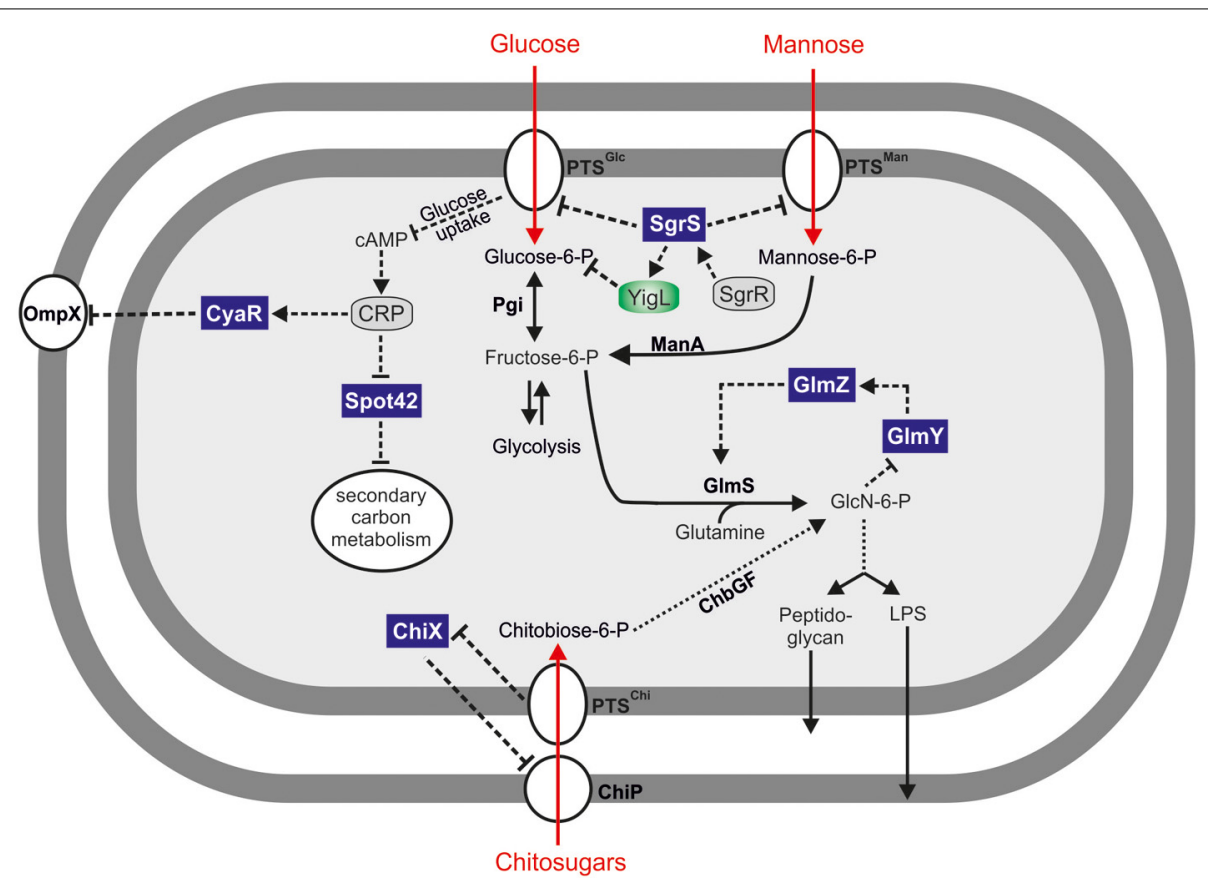

FIGURE 1 | Hfq-dependent sRNAs regulating carbon metabolism. Small RNA controlled carbohydrate metabolic pathways for uptake and metabolism of glucose, mannose, and chitosugars. Spot 42 sRNA acts as a global regulator of secondary carbon metabolism. SgrS sRNA controls uptake and secretion of various carbohydrates. The GImYZ sRNAs control the expression of glucosamine-6-phosphate synthetase (GImS) in response to its product, GlcN-6-P. Enzymes and transporters are depicted in bold and the transcriptional regulators SgrR and CRP are shown in gray.
Additional mRNA targets of SgrS have been identified (Papenfort et al., 2012). The manXYZ transcript encodes a mannose-specific uptake system and is also repressed by SgrS (Figures 1, 2; Rice and Vanderpool, 2011). However, different from the $p t s G$ mRNA, the manXYZ transcript contains two functional SgrS binding sites (Rice et al., 2012).

In Salmonella, SgrS also represses the sopD mRNA (Figure 2) (Papenfort et al., 2012) which encodes a Salmonella-specific effector protein that is injected into host cells (Brumell et al., 2003). In the host, SopD contributes to phagosome formation (Bakowski et al., 2007) and fluid secretion (Jones et al., 1998). Intriguingly, repression of the sopD mRNA requires base-pairing of SgrS to the RBS with the same conserved seed sequence that targets $p t s G$ and manXYZ (Kawamoto et al., 2006; Papenfort et al., 2012; Rice et al., 2012). Thus, the SgrS seed sequence underlying the regulation of sugar transport mRNAs has been recruited to control the mRNA of a horizontally acquired virulence gene.

The study of this non-sugar stress related sopD target has revealed the exceptional fidelity by which SgrS recognizes mRNAs. That is, many Salmonella isolates carry a duplication of the sopD gene termed sopD2 (Brumell et al., 2003); the SopD2 protein is also secreted into host cells and is required for virulence in mice (Jiang et al., 2004). However, despite extensive sequence homology between the two virulence factor mRNAs, the sopD2 mRNA is not regulated by SgrS. Genetic and biochemical analyses of the underlying mechanism revealed that a single-nucleotide variation between the two mRNA sequences is sufficient to prevent SgrS from targeting sopD2. This single nucleotide difference renders a stable G-C pair in the productive SgrS-sopD interaction into a silent G-U pair which prevents SgrS from regulating sopD2. Although the G-U pair is predicted to make only a minor difference in RNA-duplex stability, its crucial location at the proximal end of the RNA seed interaction prevents sopD2 from becoming an SgrS target (Papenfort et al., 2012). In other words, a single hydrogen bond (G-C vs. G-U pair) determines which of these two virulence factor mRNAs is regulated by SgrS.

The most recent addition to the list of SgrS target genes is the yigL mRNA (Papenfort et al., 2013) (Figure 1). Different from the hitherto known negative regulations, SgrS activates the synthesis of YigL protein (Figure 2). Importantly, the yigL gene is expressed as part of a di-cistronic pldB-yigL mRNA but the activation by SgrS is restricted to the yigL part of the transcript. The underlying activation mechanism involves basepairing of SgrS to a processed monocistronic yigL mRNA species in which SgrS sequesters a RNase E cleavage site. This sitespecific inhibition of RNase E-mediated decay increases transcript stability and YigL protein synthesis (Papenfort et al., 2013). This novel mode of post-transcriptional activation complemented previously observed mechanisms of positive regulation (Fröhlich and Vogel, 2009) and was subsequently reencountered in the activation of $c f a$ mRNA by RydC sRNA (Fröhlich et al., 2013).

The SgrS-mediated activation of yigL plays an important biological role during glucose-phosphate stress. Since it occurs within minutes, it can be considered to be part of an immediate stress response program (Papenfort et al., 2013). The yigL 


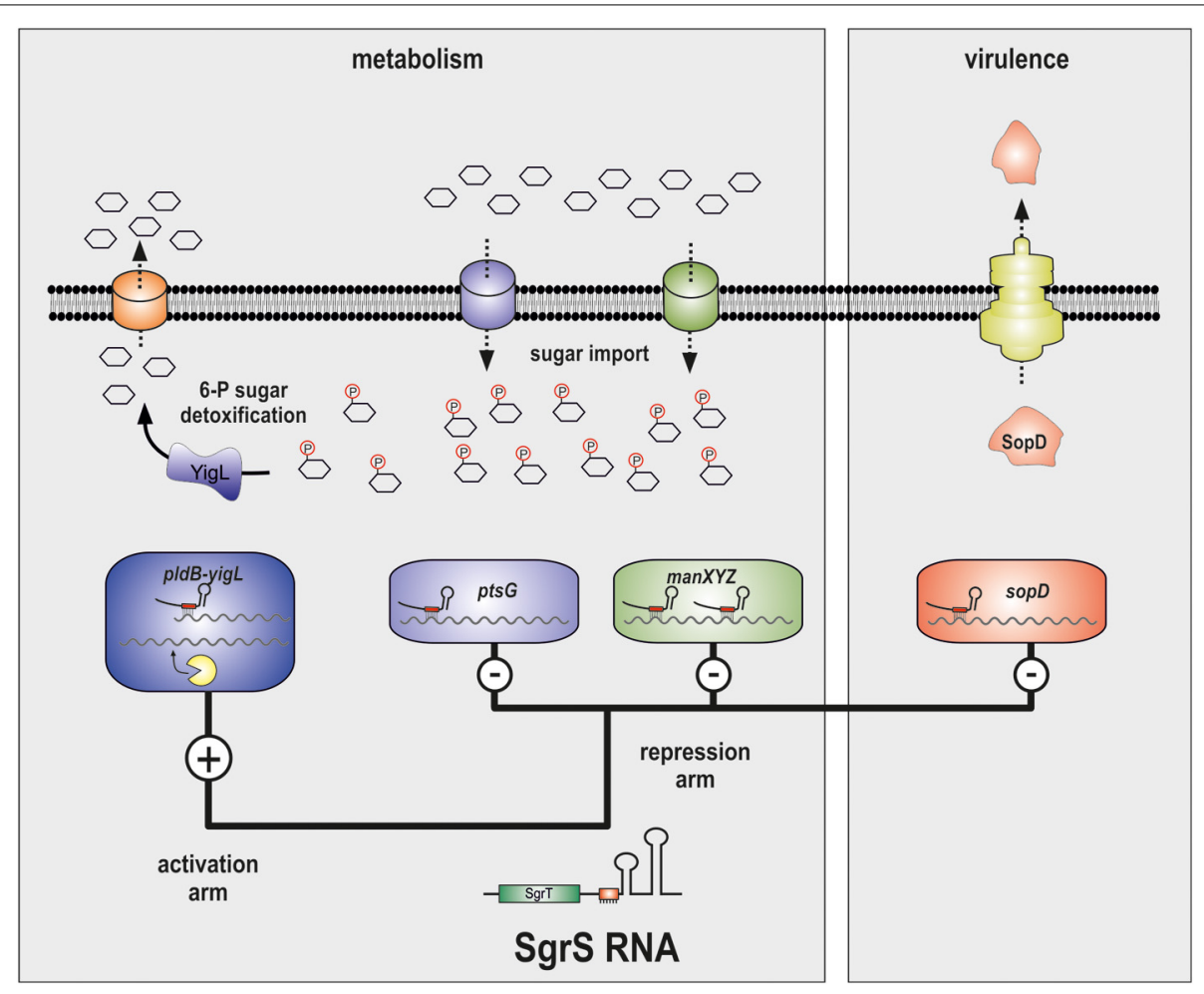

FIGURE 2 | SgrS controls carbon metabolism and virulence factor production. The SgrS sRNA regulates the $p t s G$ and man $X Y Z$, yig $L$ and sopD $m R N A s$ via direct base-pairing with the respective transcripts. Activation of $y i g L$ requires inhibition of endonucleolytic degradation through sequestration of a RNase E cleavage site. The pts $G$ and manXYZ mRNAs encode carbohydrate transporters for glucose and mannose, respectively. The yigL gene encodes a potent phosphatase which removes phosphate residues from intracellular carbohydrates which allows export. The sopD gene is specific to Salmonella and its translation results in a secreted virulence factor that enters the mammalian host cell. gene encodes a potent phosphatase which catalyzes the removal of phosphate residues from intracellular carbohydrates (Kuznetsova et al., 2006; Papenfort et al., 2013). Since the negative charge of the phosphate normally prevents the toxic carbohydrates from crossing the bacterial membrane, the dephosphorylation by YigL enables efficient export and detoxification (Papenfort et al., 2013; Sun and Vanderpool, 2013). Whether the RNA-based activation of yigL is important for Salmonella infection remains to be seen. However, we note that the $y$ igL gene is required for pathogenicity of the insect pathogen Xenorhabdus nematophila (Richards et al., 2009).

Another relevant element for instant stress relief is the SgrT peptide. In contrast to most other Hfq-binding sRNAs, SgrS does not strictly act as a non-coding regulator. The proximal part of the molecule encodes the $\sim 40$ aa SgrT peptide which can inhibit carbohydrate import, likely by blocking the glucose channel (Wadler and Vanderpool, 2007). SgrT is not required for the regulation of target mRNAs (Balasubramanian and Vanderpool, 2013) and not necessarily conserved in sgrS homologs of other species (Horler and Vanderpool, 2009).

In order to fully understand the function of SgrS in metabolism and virulence, it will be important to identify the cause of glucose-phosphate stress and the molecule(s) involved in SgrS induction in pathogenic organisms. Suppressor studies in non-pathogenic E. coli have suggested a connection of phosphate metabolism and glucose-phosphate stress (Richards and Vanderpool, 2012) and experiments from Aiba and Vanderpool groups indicated that G-6-P itself is not causing toxicity. Rather, the depletion of glycolytic intermediates induces growth arrest (Morita et al., 2003; Richards et al., 2013) but how this ties in with virulence factor control such as the observed repression of SopD synthesis in Salmonella remains to be understood.

Along the same line, robust virulence-related phenotypes of sgrS mutants are yet to be identified in Salmonella (Santiviago et al., 2009; Papenfort et al., 2012). Given the massive competition for glucose by other microbes in the intestine it is likely that SgrS-mediated gene regulation is most relevant when Salmonella has entered the host cell. Here, glucose is plentiful and serves as the primary carbon source for intracellular replication (Dandekar et al., 2012). When Salmonella disseminates systemically into the liver and spleen it continues to grow within macrophage where glycolysis and glucose metabolism remain highly relevant (Bowden et al., 2009). Therefore, regulation of glycolytic flux and virulence factor production by SgrS could be important under these conditions. In this context it is interesting to note that in $V$. cholerae a related sRNA, TarA, is required for infant mouse colonization by this pathogen. Similar to SgrS, TarA represses the production of PtsG; different from SgrS, though, the expression 
of TarA is directly controlled by a major virulence transcription factor, ToxT (Richard et al., 2010).

\section{CRP-CONTROLLED sRNAs}

Spot 42 (encoded by the spf gene) was one of the first bacterial riboregulators identified (Ikemura and Dahlberg, 1973) and it is also one of the most conserved sRNAs (Hansen et al., 2012). Transcription of Spot 42 is repressed by cAMP-bound CRP (Polayes et al., 1988) and the over-expression of this sRNA reduces growth on various carbon sources (Rice and Dahlberg, 1982; Beisel and Storz, 2011). Direct targets of Spot 42 remained elusive until in 2002, when the Valentin-Hansen lab discovered that Spot 42 associated with Hfq (Moller et al., 2002a) and regulated galactose metabolism in E. coli (Moller et al., 2002b). Specifically, they showed that Spot 42 targets the distal part of the galETKM operon mRNA by base-pairing to the RBS of the galK cistron, demonstrating for the first time that sRNAs can post-transcriptionally modulate specific genes within multi-cistronic transcripts. Such discoordinate operon expression, resulting in selective repression or activation of internal cistrons, has recently been described for other sRNAs, too (Balasubramanian and Vanderpool, 2013; Papenfort et al., 2013).

Searches for additional Spot 42 target mRNAs have since revealed a more global role for Spot 42 during glucose catabolism (Beisel and Storz, 2011; Beisel et al., 2012). Nineteen more repressed transcripts were discovered, most of which have documented functions in the transport and metabolism of secondary carbon sources. Intriguingly, many of them are regulated by CRP at the transcriptional level, suggesting that CRP and Spot 42 form a complex feed-forward loop which reinforces CCR. Here, Spot 42 directly inhibits the translation of mRNAs involved in the utilization of secondary carbon sources, the same genes which are also regulated by CRP at the transcriptional level (Beisel and Storz, 2011; Papenfort and Vogel, 2011). Since many target interactions of Spot 42 seem conserved in various enteric pathogens (Wright et al., 2013), Spot 42 may be relevant as carbon source composition change rapidly in the course of an infection process.

CyaR is another CRP-controlled sRNA which binds Hfq and is highly conserved among the enterobacteria (Zhang et al., 2003). In contrast to Spot 42 , which is repressed by CRP, CyaR is activated by the CRP-cAMP complex. One conserved target of CyaR is the ompX mRNA which encodes a major outer membrane protein of Salmonella and E. coli (Johansen et al., 2008; Papenfort et al., 2008; De Lay and Gottesman, 2009). Additional targets of CyaR include the transcripts of $y q a E$, nadE, and $l u x S$ (De Lay and Gottesman, 2009) as well as ptsI, yobF, and $s d h A$ (Wright et al., 2013), in other words, transcripts of genes that relate directly or indirectly to metabolic functions. For example, the luxS gene is required for the production of the common autoinducer $\mathrm{AI}-2$ and repression by CyaR suggests a link between carbon metabolism and population behavior (De Lay and Gottesman, 2009). Recent studies revealed the expression of several CRP-dependent sRNAs (including CyaR) in Yersinia pestis -infected lungs, suggesting a potential role for carbon metabolism and sRNAs in pathogenicity (Koo et al., 2011; Yan et al., 2013). Indeed, in Y. pestis Crp expression itself depends on the Hfq chaperone which is revelant for the development of pneumonic plague (Lathem et al., 2014).

\section{CHITIN UTILIZATION THROUGH SRNAs}

Chitin is a solid polymer made of $\mathrm{N}$-acetylglucosamine (GlcNAc) and one of the most abundant biomaterials on Earth. Thanks to its inert structure chitin requires specialized enzymes, termed chitinases, to be utilized (Bhattacharya et al., 2007). Interaction with chitin can be important during multi-species biofilm formation with fungal partners and may also affect the virulence of individual bacterial pathogens (Brandl et al., 2011 and references therein). Ecologically, chitinases play an important role in the lifestyle of many marine bacteria, e.g. V. cholerae (Meibom et al., 2004) where GlcNAc induces the expression of the competenceregulating TfoR sRNA (Yamamoto et al., 2011). Further, chitinases are also encoded by non-marine enteropathogens such as Salmonella (McClelland et al., 2001).

In E. coli and Salmonella chitin utilization is regulated by a complex mechanism involving the sRNA ChiX (a.k.a RybC, MicM, or SroB) and a decoy mRNA transcript (Mandin and Gottesman, 2009). In the absence of chitosugars, ChiX sRNA continuously binds to and represses the chiP mRNA which encodes a chitoporin required for the uptake of chitooligosaccharides (Rasmussen et al., 2009) (Figure 1). Genetic screens for relief of chiP repression by ChiX hinted at another layer of posttranscriptional control (Figueroa-Bossi et al., 2009; Overgaard et al., 2009). Here, expression of the chb operon (encoding genes for chitosugar utilization) is induced in the presence of chitobiose via the ChbR transcriptional regulator (Plumbridge and Pellegrini, 2004). Through a base-pairing interaction, the chb mRNA titrates the ChiX sRNA, inducing a rapid degradation of this repressor. This decoy function of $c h b$ indirectly increases the synthesis of the ChiP porin, adjusting its levels to the availability of the enzymes for chitosugar processing (Figueroa-Bossi et al., 2009; Overgaard et al., 2009). In addition, when chitosugar concentrations are low ChiX activity is accompanied by transcriptional repression of the chiP and chb genes by NagC. However, when chitosugars enter the cell repression by $\mathrm{NagC}$ is alleviated and $c h b$ can act as a decoy for ChiX (Plumbridge et al., 2014).

Chitin utilization is also important in the Gram positive bacterium, L. monocytogenes. Recent studies suggested that the chitinolytic activity of this pathogen could have important functions during immune evasion; in addition, mutations in the chitinase-encoding gene chiA reduced virulence (Chaudhuri et al., 2013b). Interestingly, expression of the $c h i A / B$ genes is controlled by the master virulence regulator PrfA (Larsen et al., 2010), but the levels of the chiA mRNA are additionally controlled by the Hfq-dependent LhrA sRNA (Nielsen et al., 2011). LhrA represses the translation of at least three genes, i.e., chiA, Imo0302 (hypothetical protein), and $1 m o 0880$ (cell wall associated protein). Expression of LhrA has a negative effect on the chitonolytic activity of $L$. monocytogenes, however, it is not yet clear if this function is also relevant for virulence. Note that LhrA was the first example of a sRNA from a Gram positive bacterium that requires Hfq for target regulation (Nielsen et al., 2010). 


\section{THE GImY/Z sRNAs ACT BY SEQUESTRATION AND BASE-PAIRING}

The two homologous sRNAs, GlmY and GlmZ, are highly conserved among the enterobacteriae. Both sRNAs activate production of GlmS (Figure 1), although only GlmZ directly base-pairs with the $g l m S$ transcript. The glmS mRNA accumulates as the distal part of the glmUS dicistronic transcript, and is separated from the $g l m U$ ORF by an RNase E mediated cleavage event (Kalamorz et al., 2007). Following this processing, the glmS mRNA remains translationally inactive because of an intrinsic inhibitory structure within its $5^{\prime}$ UTR. Binding of GlmZ to the $g l m S 5^{\prime}$ UTR resolves this structure, which releases the RBS of this transcripts and increases synthesis of the GlmS protein (Reichenbach et al., 2008; Urban and Vogel, 2008).

The enzymatic product of GlmS is glucosamine-6-phosphate (GlcN6P), a central aminosugar required for cell wall biosynthesis. Low levels of GlcN6P induce the expression of GlmY which indirectly activates GlmS production through GlmZ and the accessory protein, RapZ (a.k.a. YhbJ). Due to its structural similarity with GlmZ, GlmY can function through molecular mimicry to interfere with $\mathrm{GlmZ}$ degradation by RNase $\mathrm{E}$ and RapZ. The latter protein is a specialized adapter that targets $\mathrm{GlmZ}$ for RNase E-mediated decay. Recognition by RapZ is guided by a RNA element shared between GlmZ and GlmY and high levels of GlmY titrate the RapZ protein from GlmZ, thus stabilizing the GlmZ sRNA. GlmY itself does not bind Hfq, suggesting that it acts as a specific decoy for GlmZ rather than regulating mRNAs expression on its own (Gopel et al., 2013). Taken together, these two well-conserved sRNAs act hierarchically in a complex regulatory cascade to adjust the translation of the $g l m S$ mRNA to physiological needs.

In Salmonella and other enterobacteria, transcription of GlmY and GlmZ is regulated by two overlapping promoters controlled by either $\sigma^{70}$ or $\sigma^{54}$ although this may vary between species (Urban et al., 2007; Reichenbach et al., 2009; Gopel et al., 2011). GlmY expression also requires binding of the global transcriptional regulator, IHF (Gopel et al., 2011). In addition, the expression of the glm $Y / Z$ genes by the $\sigma^{54}$ version of RNA polymerase requires the QseF and QseE proteins (a.k.a. GlrR/GlrK) (Reichenbach et al., 2009; Gopel et al., 2011). Intriguingly, QseF and QseE constitute a two-component system that is important for the virulence of $Y$. pseudotuberculosis (Flamez et al., 2008) and enterohemorrhagic E. coli (EHEC) (Reading et al., 2007) indicating that GlmY/Z might have a function in virulence.

Indeed, the Sperandio group recently reported a crucial role of the GlmY/Z sRNAs for the pathogenicity of EHEC, observing that mutations of either $\operatorname{glm} Y$ or $g \operatorname{lm} Z$ increased pedestal formation on host cells by this organisms (Gruber and Sperandio, 2014). Surprisingly, GlmY/Z did not seem to control glmS expression in EHEC. Instead, both sRNAs regulated transcripts from the LEE4 and LEE5 pathogenicity islands as well as the mRNA of the secreted effector protein EspFu. This regulation is reminiscent of the above described SgrS-sopD example (Papenfort et al., 2012) in that conserved "core" sRNAs are recruited to regulate the mRNAs of horizontally acquired virulence factors through Hfq and base-pairing.

\section{GLOBAL FUNCTIONS FOR THE RNA-BINDING PROTEIN, CsrA}

CsrA-like proteins are conserved in most enteric pathogens and deletion of the csrA gene often impairs virulence (LucchettiMiganeh et al., 2008; Seyll and Van Melderen, 2013). Given the multi-faceted phenotypes of many $\operatorname{csr} A$ mutant strains, one may argue that reduced pathogenicity primarily resulted from decreased overall fitness rather than the specific virulence functions. Indeed, a Salmonella csrA mutant displayed multiple defects in metabolic regulation and virulence factor expression (Altier et al., 2000; Lawhon et al., 2003) and comparable phenotypes were observed in uropathogenic E. coli (Mitra et al., 2013). However, CsrA also regulates Salmonella pathogenicity more directly. For example, CsrA binds to the 5' UTR of the mRNA of HilD repressing the synthesis of this master transcriptional regulator of virulence (Martinez et al., 2011). Similarly, CsrA affects biofilm formation through interaction with the mRNA of an phosphodiesterase gene (STM3611) regulating intracellular c-di-GMP levels (Jonas et al., 2010). CsrA was also found to coordinate the expression of two mutually exclusive fimbrial operons in Salmonella by a putative novel mechanism of mRNA cross-regulation (Sterzenbach et al., 2013).

The global activity of CsrA in E. coli and Salmonella is counteracted by the CsrB/C sRNAs whose transcription is under control of the BarA/UvrY TCS (Gudapaty et al., 2001; Suzuki et al., 2002). Transcriptional control of the CsrA antagonists by the BarA/UvrY TCS seems to be a conserved principle in many bacteria (Seyll and Van Melderen, 2013). While some bacteria encode only one CsrB-like RNA, V. cholerae species encode three different CsrA antagonists: CsrB, CsrC, and CsrD (Lenz et al., 2005). Here, expression of the Csr-sRNAs affects virulence via regulation of the quorum sensing pathway (Jang et al., 2010). In addition, expression of CsrB-like sRNAs can also be controlled post-transcriptionally. The CsrD RNA-binding protein of E. coli (not to be confused with the CsrD sRNA from $V$. cholerae) can bind the CsrB/C sRNAs and target them for degradation by RNase E (Suzuki et al., 2006). CsrA also reduces the expression of CsrD (Jonas et al., 2008) generating a negative feedback loop for robust signaling under conditions of stress (Adamson and Lim, 2013).

The Csr system and its relevance for virulence and metabolism have been studied in greater detail for the human enteropathogen Y. pseudotuberculosis where a mutation of the $c s r A$ gene resulted in complex phenotypic alterations (Heroven et al., 2008). Transcriptomic studies revealed deregulation of $\sim 500$ ORFs in the csrA mutants, $\sim 20 \%$ of which are metabolic genes (Heroven et al., 2012a). The Y. pseudotuberculosis genome encodes two CsrB-like sRNAs (CsrB and CsrC) and their expression is crucial during the initial phase of infection because sequestration of CsrA is needed to allow the production of the host cell adhesion factor, InvA (Heroven et al., 2008). Induction of InvA involves a complex regulon including the transcriptional factor RovA (Heroven and Dersch, 2006). Regulation via the Csr-system is further controlled via CCR. The CRP protein represses the response regulator UvrY which is required for CsrB activation. A crp mutant has increased levels of the CsrB sRNA which promotes CsrC and RovA repression. Not surprisingly, a Y. pseudotuberculosis mutant lacking the $\operatorname{crp}$ gene is strongly impaired in virulence (Heroven et al., 2012b). 


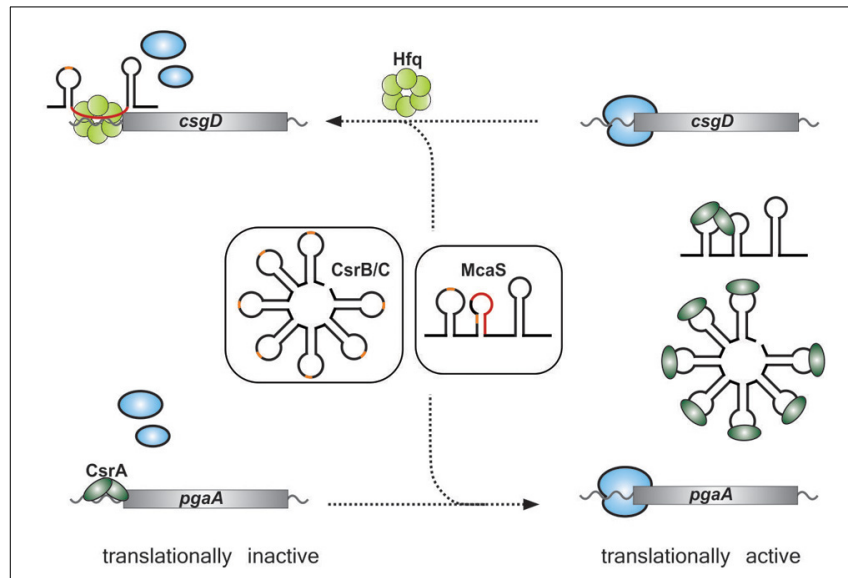

FIGURE 3 | Overlap of the CsrA and Hfq regulons through McaS. Both McaS and the CsrB-like sRNAs bind to the CsrA protein via GGA-rich motifs (orange). Binding of CsrA results in titration of CsrA from its target mRNAs which usually activates their translation (lower panel). In addition, McaS can also directly bind and regulate target mRNAs (e.g. $\operatorname{csg} D$ ) through Hfq-mediated base-pairing (indicated in red).

A new type of CsrA antagonist has recently been reported in E. coli. It was observed that the Hfq-binding sRNA, McaS, which regulates the $f h l D$ and $\operatorname{csg} D$ mRNAs (encoding regulators of motility and biofilm formation, respectively) by base pairing interactions, impacted expression of the pgaA gene by a supposedly indirect mechanism (Jorgensen et al., 2012; Thomason et al., 2012) (Figure 3). The PgaA protein is crucial for the production of PGA (poly- $\beta$-1,6-N-acetyl-glucosamine), an important factor for biofilm adhesion (Itoh et al., 2008). Expression of pgaA had been known to be subject to control by CsrA (Wang et al., 2005), which suggested a link between McaS and CsrA. Indeed, the McaS sRNA was found to bind the CsrA protein via two exposed GGA motifs and thereby indirectly regulate the expression of several CsrA-target genes, including pgaA (Jorgensen et al., 2013) (Figure 3). In summary, McaS is the first sRNA regulating target gene expression via both $\mathrm{Hfq}$ and CsrA. Future studies may reveal additional sRNAs that serve in both of these global post-transcriptional networks.

\section{FUTURE DIRECTIONS}

The above examples of sRNA-mediated gene regulation in enteric pathogens serve to illustrate the growing number of potential post-transcriptional links between metabolic and virulence functions in these organisms. To date, many of these links remain inferences from functional studies of sRNA-mRNA interactions, and how these contribute to nutritional adjustment and control of virulence factor expression requires more detailed studies. However, it is important to note that global studies of the RNA targets of Hfq and CsrA, two proteins that each may control up to $20 \%$ of all mRNAs in enteric model organisms (Chao and Vogel, 2010; Romeo et al., 2013), revealed a high number of mRNAs from metabolic and virulence pathways, suggesting that many more sRNAs could be involved in these pathways. In addition, the growing depths of NGS will soon allow us to extensively profile bacterial RNA expression in complex tissue and inside host cells, even simultaneously with gene expression of the eukaryotic host to inform details of the pathogen's metabolic environment (Westermann et al., 2012).

There are more potential links between virulence and metabolism in the available sRNA data whose physiological importance needs to be explored. For example, the recent profiling of Hfq-bound Salmonella transcripts revealed the DapZ sRNA, which is encoded in the $3^{\prime}$ UTR of the well-conserved metabolic $d a p B$ gene. In Salmonella, the horizontally acquired virulence regulator HilD has been recruited to transcriptionally activate the DapZ sRNA which then acts to repress the synthesis of oligopeptide uptake proteins (Chao et al., 2012). Under regular growth conditions oligopeptide uptake is controlled by the conserved GcvB sRNA (Sharma et al., 2011) and regulation of DapZ by HilD enables the cell to exert a similar function under virulence-related conditions. However, why DapZ is linked to $\operatorname{dap}_{\mathrm{p}}$ and how the metabolic function of the DapB protein, an enzyme that produces the lysine precursor diaminopimelate, may be interwoven with a DapZ-mediated repression of amino acid uptake, is far from obvious. Of note, regulation of oligopeptide uptake through sRNAs has been observed in non-enteric bacteria, too. The RsaE sRNA from Staphyloccus aureus, which is also conserved in other Gram positives, directly controls the mRNA encoding the OppB protein (Geissmann et al., 2009) and several other transcripts of metabolic genes (Bohn et al., 2010).

The most recent count for sRNA regulators in Salmonella revealed $\sim 280$ sRNAs, many of which are Hfq-dependent and expressed under stress or virulence mimicking conditions (Kroger et al., 2012, 2013). How many of these sRNAs are also relevant for virulence is still an open question but novel approaches such as Tn-Seq (combining transposon mutagenesis and HTPS) could be powerful tools to evaluate the roles of sRNAs during infection (Van Opijnen and Camilli, 2013). The same technology can also be used to identify metabolic genes required for infection. Indeed, two recent studies using Tn-Seq in Salmonella or $V$. cholerae identified several genes involved in carbon metabolism to be required for full pathogenicity (Chaudhuri et al., 2013a; Fu et al., 2013).

Probably one of the most exciting areas of host-microbe interaction today is how pathogens deal with the commensal microbiota of the host. It is now understood that the carbohydrate metabolism of the microbiota significantly impacts on the virulence gene expression of enteric pathogens and that carbohydrates can function as signaling molecules in the intestine (Pacheco et al., 2012). In contrast, close to nothing is known about how sRNAs shape the interaction of pathogens with commensals and we are yet to see if such sRNAs would also impact virulence. Again, NGS-based metatranscriptomics of multi-species intestinal communities could provide a valuable starting point to address the relevance of regulatory RNAs and metabolic genes in the context of the host microbiota (Xiong et al., 2012). These new exciting venues at the interface of microbiology and host-microbe interaction might become relevant for the design of alternative anti-microbial compounds which consider both, the pathogen and the host microbiota. 


\section{ACKNOWLEDGMENTS}

We thank Cari Vanderpool, Chase Beisel, and Kathrin Fröhlich for comments on the manuscript. This work was funded by support from the DFG Priority Program SPP1316 (Vo875/6-1), the Bavarian BioSysNet program, and a BMBF RNASys grant. Kai Papenfort was supported by a postdoctoral fellowship from the Human Frontiers in Science Program (HFSP).

\section{REFERENCES}

Adamson, D. N., and Lim, H. N. (2013). Rapid and robust signaling in the CsrA cascade via RNA-protein interactions and feedback regulation. Proc. Natl. Acad. Sci. U.S.A. 110, 13120-13125. doi: 10.1073/pnas.1308476110

Altier, C., Suyemoto, M., and Lawhon, S. D. (2000). Regulation of Salmonella enterica serovar typhimurium invasion genes by csrA. Infect. Immun. 68, 6790-6797. doi: 10.1128/IAI.68.12.6790-6797.2000

Babitzke, P., and Romeo, T. (2007). CsrB sRNA family: sequestration of RNA-binding regulatory proteins. Curr. Opin. Microbiol. 10, 156-163. doi: 10.1016/j.mib.2007.03.007

Bakowski, M. A., Cirulis, J. T., Brown, N. F., Finlay, B. B., and Brumell, J. H. (2007). SopD acts cooperatively with SopB during Salmonella enterica serovar Typhimurium invasion. Cell. Microbiol. 9, 2839-2855. doi: 10.1111/j.14625822.2007.01000.x

Balasubramanian, D., and Vanderpool, C. K. (2013). Deciphering the interplay between two independent functions of the small RNA regulator SgrS in Salmonella. J. Bacteriol. 195, 4620-4630. doi: 10.1128/JB.00586-13

Beisel, C. L., and Storz, G. (2011). The base-pairing RNA spot 42 participates in a multioutput feedforward loop to help enact catabolite repression in Escherichia coli. Mol. Cell. 41, 286-297. doi: 10.1016/j.molcel.2010.12.027

Beisel, C. L., Updegrove, T. B., Janson, B. J., and Storz, G. (2012). Multiple factors dictate target selection by Hfq-binding small RNAs. EMBO J. 31, 1961-1974. doi: 10.1038/emboj.2012.52

Bhattacharya, D., Nagpure, A., and Gupta, R. K. (2007). Bacterial chitinases: properties and potential. Crit. Rev. Biotechnol. 27, 21-28. doi: $10.1080 / 07388550601168223$

Bobrovskyy, M., and Vanderpool, C. K. (2013). Regulation of bacterial metabolism by small rnas using diverse mechanisms. Annu. Rev. Genet. 47, 209-232. doi: 10.1146/annurev-genet-111212-133445

Bohme, K., Steinmann, R., Kortmann, J., Seekircher, S., Heroven, A. K., Berger, E., et al. (2012). Concerted actions of a thermo-labile regulator and a unique intergenic RNA thermosensor control Yersinia virulence. PLoS Pathog. 8:e1002518. doi: 10.1371/journal.ppat.1002518

Bohn, C., Rigoulay, C., Chabelskaya, S., Sharma, C. M., Marchais, A., Skorski, P., et al. (2010). Experimental discovery of small RNAs in Staphylococcus aureus reveals a riboregulator of central metabolism. Nucleic Acids Res. 38, 6620-6636. doi: 10.1093/nar/gkq462

Bowden, S. D., Rowley, G., Hinton, J. C., and Thompson, A. (2009). Glucose and glycolysis are required for the successful infection of macrophages and mice by Salmonella enterica serovar typhimurium. Infect. Immun. 77, 3117-3126. doi: 10.1128/IAI.00093-09

Brandl, M. T., Carter, M. Q., Parker, C. T., Chapman, M. R., Huynh, S., and Zhou, Y. (2011). Salmonella biofilm formation on Aspergillus niger involves cellulose-chitin interactions. PLoS ONE 6:e25553. doi: 10.1371/journal.pone. 0025553

Brumell, J. H., Kujat-Choy, S., Brown, N. F., Vallance, B. A., Knodler, L. A., and Finlay, B. B. (2003). SopD2 is a novel type III secreted effector of Salmonella typhimurium that targets late endocytic compartments upon delivery into host cells. Traffic 4, 36-48. doi: 10.1034/j.1600-0854.2003.40106.x

Caldelari, I., Chao, Y., Romby, P., and Vogel, J. (2013). RNA-mediated regulation in pathogenic bacteria. Cold Spring Harb. Perspect. Med. 3:a010298. doi: 10.1101/cshperspect.a010298

Chao, Y., Papenfort, K., Reinhardt, R., Sharma, C. M., and Vogel, J. (2012). An atlas of Hfq-bound transcripts reveals $3^{\prime}$ UTRs as a genomic reservoir of regulatory small RNAs. EMBO J. 31, 4005-4019. doi: 10.1038/emboj.2012.229

Chao, Y., and Vogel, J. (2010). The role of Hfq in bacterial pathogens. Curr. Opin. Microbiol. 13, 24-33. doi: 10.1016/j.mib.2010.01.001

Chaudhuri, R. R., Morgan, E., Peters, S. E., Pleasance, S. J., Hudson, D. L., Davies, H. M., et al. (2013a). Comprehensive assignment of roles for Salmonella typhimurium genes in intestinal colonization of food-producing animals. PLoS Genet. 9:e1003456. doi: 10.1371/journal.pgen.1003456

Chaudhuri, S., Gantner, B. N., Ye, R. D., Cianciotto, N. P., and Freitag, N. E. (2013b). The Listeria monocytogenes ChiA chitinase enhances virulence through suppression of host innate immunity. MBio 4, e00617-e00612. doi: 10.1128/mBio.00617-12

Corcoran, C. P., Podkaminski, D., Papenfort, K., Urban, J. H., Hinton, J. C., and Vogel, J. (2012). Superfolder GFP reporters validate diverse new mRNA targets of the classic porin regulator, MicF RNA. Mol. Microbiol. 84, 428-445. doi: 10.1111/j.1365-2958.2012.08031.x

Curtiss, R. 3rd., and Kelly, S. M. (1987). Salmonella typhimurium deletion mutants lacking adenylate cyclase and cyclic AMP receptor protein are avirulent and immunogenic. Infect. Immun. 55, 3035-3043.

Dandekar, T., Astrid, F., Jasmin, P., and Hensel, M. (2012). Salmonella enterica: a surprisingly well-adapted intracellular lifestyle. Front. Microbiol. 3:164. doi: 10.3389/fmicb.2012.00164

De Lay, N., and Gottesman, S. (2009). The Crp-activated small noncoding regulatory RNA CyaR (RyeE) links nutritional status to group behavior. J. Bacteriol. 191, 461-476. doi: 10.1128/JB.01157-08

Deutscher, J., Francke, C., and Postma, P. W. (2006). How phosphotransferase system-related protein phosphorylation regulates carbohydrate metabolism in bacteria. Microbiol. Mol. Biol. Rev. 70, 939-1031. doi: 10.1128/MMBR. 00024-06

Dugar, G., Herbig, A., Forstner, K. U., Heidrich, N., Reinhardt, R., Nieselt, K., et al. (2013). High-resolution transcriptome maps reveal strain-specific regulatory features of multiple Campylobacter jejuni isolates. PLoS Genet. 9:e1003495. doi: 10.1371/journal.pgen.1003495

Figueroa-Bossi, N., Valentini, M., Malleret, L., Fiorini, F., and Bossi, L. (2009). Caught at its own game: regulatory small RNA inactivated by an inducible transcript mimicking its target. Genes Dev. 23, 2004-2015. doi: 10.1101/gad.541609

Finn, R. D., Bateman, A., Clements, J., Coggill, P., Eberhardt, R. Y., Eddy, S. R., et al. (2014). Pfam: the protein families database. Nucleic Acids Res. 42, D222-D230. doi: $10.1093 /$ nar/gkt1223

Flamez, C., Ricard, I., Arafah, S., Simonet, M., and Marceau, M. (2008). Phenotypic analysis of Yersinia pseudotuberculosis 32777 response regulator mutants: new insights into two-component system regulon plasticity in bacteria. Int. J. Med. Microbiol. 298, 193-207. doi: 10.1016/j.ijmm.2007.05.005

Fröhlich, K. S., Papenfort, K., Berger, A. A., and Vogel, J. (2012). A conserved RpoSdependent small RNA controls the synthesis of major porin OmpD. Nucleic Acids Res. 40, 3623-3640. doi: 10.1093/nar/gkr1156

Fröhlich, K. S., Papenfort, K., Fekete, A., and Vogel, J. (2013). A small RNA activates CFA synthase by isoform-specific mRNA stabilization. EMBO J. 32, 2963-2979. doi: 10.1038/emboj.2013.222

Fröhlich, K. S., and Vogel, J. (2009). Activation of gene expression by small RNA. Curr. Opin. Microbiol. 12, 674-682. doi: 10.1016/j.mib.2009.09.009

Fu, Y., Waldor, M. K., and Mekalanos, J. J. (2013). Tn-Seq analysis of Vibrio cholerae intestinal colonization reveals a role for T6SS-mediated antibacterial activity in the host. Cell Host Microbe 14, 652-663. doi: 10.1016/j.chom.2013.11.001

Geissmann, T., Chevalier, C., Cros, M. J., Boisset, S., Fechter, P., Noirot, C., et al. (2009). A search for small noncoding RNAs in Staphylococcus aureus reveals a conserved sequence motif for regulation. Nucleic Acids Res. 37, 7239-7257. doi: $10.1093 / \mathrm{nar} / \mathrm{gkp} 668$

Gopel, Y., Luttmann, D., Heroven, A. K., Reichenbach, B., Dersch, P., and Gorke, B. (2011). Common and divergent features in transcriptional control of the homologous small RNAs GlmY and GlmZ in Enterobacteriaceae. Nucleic Acids Res. 39, 1294-1309. doi: 10.1093/nar/gkq986

Gopel, Y., Papenfort, K., Reichenbach, B., Vogel, J., and Gorke, B. (2013). Targeted decay of a regulatory small RNA by an adaptor protein for RNase E and counteraction by an anti-adaptor RNA. Genes Dev. 27, 552-564. doi: 10.1101/gad.210112.112

Gorke, B., and Stulke, J. (2008). Carbon catabolite repression in bacteria: many ways to make the most out of nutrients. Nat. Rev. Microbiol. 6, 613-624. doi: 10.1038/nrmicro1932

Gotz, A., Eylert, E., Eisenreich, W., and Goebel, W. (2010). Carbon metabolism of enterobacterial human pathogens growing in epithelial colorectal adenocarcinoma (Caco-2) cells. PLoS ONE 5:e10586. doi: 10.1371/journal.pone.0010586

Gruber, C. C., and Sperandio, V. (2014). Posttranscriptional control of microbeinduced rearrangement of host cell actin. MBio 5, e01025-e01013. doi: 10.1128/mBio.01025-13 
Gudapaty, S., Suzuki, K., Wang, X., Babitzke, P., and Romeo, T. (2001). Regulatory interactions of Csr components: the RNA binding protein CsrA activates csrB transcription in Escherichia coli. J. Bacteriol. 183, 6017-6027. doi: 10.1128/JB.183.20.6017-6027.2001

Hansen, G. A., Ahmad, R., Hjerde, E., Fenton, C. G., Willassen, N. P., and Haugen, P. (2012). Expression profiling reveals Spot 42 small RNA as a key regulator in the central metabolism of Aliivibrio salmonicida. BMC Genomics 13:37. doi: 10.1186/1471-2164-13-37

Hautefort, I., Thompson, A., Eriksson-Ygberg, S., Parker, M. L., Lucchini, S., Danino, V., et al. (2008). During infection of epithelial cells Salmonella enterica serovar Typhimurium undergoes a time-dependent transcriptional adaptation that results in simultaneous expression of three type 3 secretion systems. Cell. Microbiol. 10, 958-984. doi: 10.1111/j.1462-5822.2007.01099.x

Heroven, A. K., Bohme, K., and Dersch, P. (2012a). The Csr/Rsm system of Yersinia and related pathogens: a post-transcriptional strategy for managing virulence. RNA Biol. 9, 379-391. doi: 10.4161/rna.19333

Heroven, A. K., Bohme, K., Rohde, M., and Dersch, P. (2008). A Csr-type regulatory system, including small non-coding RNAs, regulates the global virulence regulator RovA of Yersinia pseudotuberculosis through RovM. Mol. Microbiol. 68, 1179-1195. doi: 10.1111/j.1365-2958.2008.06218.x

Heroven, A. K., and Dersch, P. (2006). RovM, a novel LysR-type regulator of the virulence activator gene rovA, controls cell invasion, virulence and motility of Yersinia pseudotuberculosis. Mol. Microbiol. 62, 1469-1483. doi: 10.1111/j.13652958.2006.05458.x

Heroven, A. K., Sest, M., Pisano, F., Scheb-Wetzel, M., Steinmann, R., Bohme, K., et al. (2012b). Crp induces switching of the CsrB and CsrC RNAs in Yersinia pseudotuberculosis and links nutritional status to virulence. Front. Cell. Infect. Microbiol. 2:158. doi: 10.3389/fcimb.2012.00158

Horler, R. S., and Vanderpool, C. K. (2009). Homologs of the small RNA SgrS are broadly distributed in enteric bacteria but have diverged in size and sequence. Nucleic Acids Res. 37, 5465-5476. doi: 10.1093/nar/gkp501

Ikemura, T., and Dahlberg, J. E. (1973). Small ribonucleic acids of Escherichia coli. II. noncoordinate accumulation during stringent control. J. Biol. Chem. 248, 5033-5041.

Irani, M. H., and Maitra, P. K. (1977). Properties of Escherichia coli mutants deficient in enzymes of glycolysis. J. Bacteriol. 132, 398-410.

Ishikawa, H., Otaka, H., Maki, K., Morita, T., and Aiba, H. (2012). The functional Hfq-binding module of bacterial sRNAs consists of a double or single hairpin preceded by a U-rich sequence and followed by a $3^{\prime}$ poly(U) tail. RNA 18 , 1062-1074. doi: 10.1261/rna.031575.111

Itoh, Y., Rice, J. D., Goller, C., Pannuri, A., Taylor, J., Meisner, J., et al. (2008). Roles of pgaABCD genes in synthesis, modification, and export of the Escherichia coli biofilm adhesin poly-beta-1,6-N-acetyl-D-glucosamine. J. Bacteriol. 190, 3670-3680. doi: 10.1128/JB.01920-07

Jahreis, K., Pimentel-Schmitt, E. F., Bruckner, R., and Titgemeyer, F. (2008). Ins and outs of glucose transport systems in eubacteria. FEMS Microbiol. Rev. 32, 891-907. doi: 10.1111/j.1574-6976.2008.00125.x

Jang, J., Jung, K. T., Yoo, C. K., and Rhie, G. E. (2010). Regulation of hemagglutinin/protease expression by the VarS/VarA-CsrA/B/C/D system in Vibrio cholerae. Microb. Pathog. 48, 245-250. doi: 10.1016/j.micpath.2010.03.003

Jiang, X., Rossanese, O. W., Brown, N. F., Kujat-Choy, S., Galan, J. E., Finlay, B. B., et al. (2004). The related effector proteins SopD and SopD2 from Salmonella enterica serovar Typhimurium contribute to virulence during systemic infection of mice. Mol. Microbiol. 54, 1186-1198. doi: 10.1111/j.1365-2958.2004.04344.x

Johansen, J., Eriksen, M., Kallipolitis, B., and Valentin-Hansen, P. (2008). Downregulation of outer membrane proteins by noncoding RNAs: unraveling the cAMP-CRP- and sigmaE-dependent CyaR-ompX regulatory case. J. Mol. Biol. 383, 1-9. doi: 10.1016/j.jmb.2008.06.058

Johansson, J., Mandin, P., Renzoni, A., Chiaruttini, C., Springer, M., and Cossart, P. (2002). An RNA thermosensor controls expression of virulence genes in Listeria monocytogenes. Cell 110, 551-561. doi: 10.1016/S0092-8674(02)00905-4

Jonas, K., Edwards, A. N., Ahmad, I., Romeo, T., Romling, U., and Melefors, O. (2010). Complex regulatory network encompassing the Csr, c-di-GMP and motility systems of Salmonella Typhimurium. Environ. Microbiol. 12, 524-540. doi: 10.1111/j.1462-2920.2009.02097.x

Jonas, K., Edwards, A. N., Simm, R., Romeo, T., Romling, U., and Melefors, O. (2008). The RNA binding protein CsrA controls cyclic di-GMP metabolism by directly regulating the expression of GGDEF proteins. Mol. Microbiol. 70, 236-257. doi: 10.1111/j.1365-2958.2008.06411.x
Jones, M. A., Wood, M. W., Mullan, P. B., Watson, P. R., Wallis, T. S., and Galyov, E. E. (1998). Secreted effector proteins of Salmonella dublin act in concert to induce enteritis. Infect. Immun. 66, 5799-5804.

Jorgensen, M. G., Nielsen, J. S., Boysen, A., Franch, T., Moller-Jensen, J., and Valentin-Hansen, P. (2012). Small regulatory RNAs control the multicellular adhesive lifestyle of Escherichia coli. Mol. Microbiol. 84, 36-50. doi: 10.1111/j.1365-2958.2012.07976.x

Jorgensen, M. G., Thomason, M. K., Havelund, J., Valentin-Hansen, P., and Storz, G. (2013). Dual function of the McaS small RNA in controlling biofilm formation. Genes Dev. 27, 1132-1145. doi: 10.1101/gad.214734.113

Kadner, R. J., Murphy, G. P., and Stephens, C. M. (1992). Two mechanisms for growth inhibition by elevated transport of sugar phosphates in Escherichia coli. J. Gen. Microbiol. 138, 2007-2014. doi: 10.1099/00221287-138-10-2007

Kalamorz, F., Reichenbach, B., Marz, W., Rak, B., and Gorke, B. (2007). Feedback control of glucosamine-6-phosphate synthase GlmS expression depends on the small RNA GlmZ and involves the novel protein YhbJ in Escherichia coli. Mol. Microbiol. 65, 1518-1533. doi: 10.1111/j.1365-2958.2007.05888.x

Kawamoto, H., Koide, Y., Morita, T., and Aiba, H. (2006). Base-pairing requirement for RNA silencing by a bacterial small RNA and acceleration of duplex formation by Hfq. Mol. Microbiol. 61, 1013-1022. doi: 10.1111/j.13652958.2006.05288.x

Kawamoto, H., Morita, T., Shimizu, A., Inada, T., and Aiba, H. (2005). Implication of membrane localization of target mRNA in the action of a small RNA: mechanism of post-transcriptional regulation of glucose transporter in Escherichia coli. Genes Dev. 19, 328-338. doi: 10.1101/gad.1270605

Kim, T. J., Chauhan, S., Motin, V. L., Goh, E. B., Igo, M. M., and Young, G. M. (2007). Direct transcriptional control of the plasminogen activator gene of Yersinia pestis by the cyclic AMP receptor protein. J. Bacteriol. 189, 8890-8900. doi: 10.1128/JB.00972-07

Kimata, K., Tanaka, Y., Inada, T., and Aiba, H. (2001). Expression of the glucose transporter gene, ptsG, is regulated at the mRNA degradation step in response to glycolytic flux in Escherichia coli. EMBO J. 20, 3587-3595. doi: 10.1093/emboj/20.13.3587

Koo, J. T., Alleyne, T. M., Schiano, C. A., Jafari, N., and Lathem, W. W. (2011). Global discovery of small RNAs in Yersinia pseudotuberculosis identifies Yersiniaspecific small, noncoding RNAs required for virulence. Proc. Natl. Acad. Sci. U.S.A. 108, E709-E717. doi: 10.1073/pnas.1101655108

Kortmann, J., and Narberhaus, F. (2012). Bacterial RNA thermometers: molecular zippers and switches. Nat. Rev. Microbiol. 10, 255-265. doi: 10.1038/nrmicro2730

Kroger, C., Colgan, A., Srikumar, S., Handler, K., Sivasankaran, S. K., Hammarlof, D. L., et al. (2013). An infection-relevant transcriptomic compendium for Salmonella enterica Serovar Typhimurium. Cell Host Microbe 14, 683-695. doi: 10.1016/j.chom.2013.11.010

Kroger, C., Dillon, S. C., Cameron, A. D., Papenfort, K., Sivasankaran, S. K., Hokamp, K., et al. (2012). The transcriptional landscape and small RNAs of Salmonella enterica serovar Typhimurium. Proc. Natl. Acad. Sci. U.S.A. 109, E1277-E1286. doi: 10.1073/pnas.1201061109

Kuznetsova, E., Proudfoot, M., Gonzalez, C. F., Brown, G., Omelchenko, M. V., Borozan, I., et al. (2006). Genome-wide analysis of substrate specificities of the Escherichia coli haloacid dehalogenase-like phosphatase family. J. Biol. Chem. 281, 36149-36161. doi: 10.1074/jbc.M605449200

Larsen, M. H., Leisner, J. J., and Ingmer, H. (2010). The chitinolytic activity of Listeria monocytogenes EGD is regulated by carbohydrates but also by the virulence regulator PrfA. Appl. Environ. Microbiol. 76, 6470-6476. doi: 10.1128/AEM.00297-10

Lathem, W. W., Schroeder, J. A., Bellows, L. E., Ritzert, J. T., Koo, J. T., Price, P. A., et al. (2014). Posttranscriptional regulation of the Yersinia pestis cyclic AMP receptor protein Crp and impact on virulence. MBio 5, e01038-e01013. doi: 10.1128/mBio.01038-13

Lawhon, S. D., Frye, J. G., Suyemoto, M., Porwollik, S., McClelland, M., and Altier, C. (2003). Global regulation by CsrA in Salmonella typhimurium. Mol. Microbiol. 48, 1633-1645. doi: 10.1046/j.1365-2958.2003.03535.x

Lee, A. T., and Cerami, A. (1987). Elevated glucose 6-phosphate levels are associated with plasmid mutations in vivo. Proc. Natl. Acad. Sci. U.S.A. 84, 8311-8314. doi: 10.1073/pnas.84.23.8311

Lenz, D. H., Miller, M. B., Zhu, J., Kulkarni, R. V., and Bassler, B. L. (2005). CsrA and three redundant small RNAs regulate quorum sensing in Vibrio cholerae. Mol. Microbiol. 58, 1186-1202. doi: 10.1111/j.1365-2958.2005.04902.x 
Lenz, D. H., Mok, K. C., Lilley, B. N., Kulkarni, R. V., Wingreen, N. S., and Bassler, B. L. (2004). The small RNA chaperone Hfq and multiple small RNAs control quorum sensing in Vibrio harveyi and Vibrio cholerae. Cell 118, 69-82. doi: 10.1016/j.cell.2004.06.009

Loh, E., Dussurget, O., Gripenland, J., Vaitkevicius, K., Tiensuu, T., Mandin, P., et al. (2009). A trans-acting riboswitch controls expression of the virulence regulator PrfA in Listeria monocytogenes. Cell 139, 770-779. doi: 10.1016/j.cell.2009.08.046

Loh, E., Kugelberg, E., Tracy, A., Zhang, Q., Gollan, B., Ewles, H., et al. (2013). Temperature triggers immune evasion by Neisseria meningitidis. Nature 502, 237-240. doi: 10.1038/nature12616

Lucchetti-Miganeh, C., Burrowes, E., Baysse, C., and Ermel, G. (2008). The posttranscriptional regulator CsrA plays a central role in the adaptation of bacterial pathogens to different stages of infection in animal hosts. Microbiology 154, 16-29. doi: 10.1099/mic.0.2007/012286-0

Maki, K., Morita, T., Otaka, H., and Aiba, H. (2010). A minimal base-pairing region of a bacterial small RNA SgrS required for translational repression of ptsG mRNA. Mol. Microbiol. 76, 782-792. doi: 10.1111/j.1365-2958.2010.07141.x

Mandin, P., and Gottesman, S. (2009). Regulating the regulator: an RNA decoy acts as an OFF switch for the regulation of an sRNA. Genes Dev. 23, 1981-1985. doi: 10.1101/gad.1846609

Martinez, L. C., Yakhnin, H., Camacho, M. I., Georgellis, D., Babitzke, P., Puente, J. L., et al. (2011). Integration of a complex regulatory cascade involving the SirA/BarA and Csr global regulatory systems that controls expression of the Salmonella SPI-1 and SPI-2 virulence regulons through HilD. Mol. Microbiol. 80, 1637-1656. doi: 10.1111/j.1365-2958.2011.07674.x

McClelland, M., Sanderson, K. E., Spieth, J., Clifton, S. W., Latreille, P., Courtney, L., et al. (2001). Complete genome sequence of Salmonella enterica serovar Typhimurium LT2. Nature 413, 852-856. doi: 10.1038/35101614

Meibom, K. L., Li, X. B., Nielsen, A. T., Wu, C. Y., Roseman, S., and Schoolnik, G. K. (2004). The Vibrio cholerae chitin utilization program. Proc. Natl. Acad. Sci. U.S.A. 101, 2524-2529. doi: 10.1073/pnas.0308707101

Mitra, A., Palaniyandi, S., Herren, C. D., Zhu, X., and Mukhopadhyay, S. (2013). Pleiotropic roles of uvrY on biofilm formation, motility and virulence in uropathogenic Escherichia coli CFT073. PLoS ONE 8:e55492. doi: 10.1371/journal.pone.0055492

Moller, T., Franch, T., Hojrup, P., Keene, D. R., Bachinger, H. P., Brennan, R. G., et al. (2002a). Hfq: a bacterial Sm-like protein that mediates RNA-RNA interaction. Mol. Cell 9, 23-30. doi: 10.1016/S1097-2765(01)00436-1

Moller, T., Franch, T., Udesen, C., Gerdes, K., and Valentin-Hansen, P. (2002b). Spot 42 RNA mediates discoordinate expression of the E. coli galactose operon. Genes Dev. 16, 1696-1706. doi: 10.1101/gad.231702

Monteiro, C., Papenfort, K., Hentrich, K., Ahmad, I., Le Guyon, S., Reimann, R., et al. (2012). Hfq and Hfq-dependent small RNAs are major contributors to multicellular development in Salmonella enterica serovar Typhimurium. RNA Biol. 9, 489-502. doi: 10.4161/rna.19682

Morita, T., El-Kazzaz, W., Tanaka, Y., Inada, T., and Aiba, H. (2003). Accumulation of glucose 6-phosphate or fructose 6-phosphate is responsible for destabilization of glucose transporter mRNA in Escherichia coli. J. Biol. Chem. 278, 15608-15614. doi: 10.1074/jbc.M300177200

Morita, T., Maki, K., and Aiba, H. (2005). RNase E-based ribonucleoprotein complexes: mechanical basis of mRNA destabilization mediated by bacterial noncoding RNAs. Genes Dev. 19, 2176-2186. doi: 10.1101/gad. 1330405

Morita, T., Mochizuki, Y., and Aiba, H. (2006). Translational repression is sufficient for gene silencing by bacterial small noncoding RNAs in the absence of mRNA destruction. Proc. Natl. Acad. Sci. U.S.A. 103, 4858-4863. doi: 10.1073/pnas.0509638103

Murphy, E. R., and Payne, S. M. (2007). RyhB, an iron-responsive small RNA molecule, regulates Shigella dysenteriae virulence. Infect. Immun. 75, 3470-3477. doi: 10.1128/IAI.00112-07

Nielsen, J. S., Larsen, M. H., Lillebaek, E. M., Bergholz, T. M., Christiansen, M. H., Boor, K. J., et al. (2011). A small RNA controls expression of the chitinase ChiA in Listeria monocytogenes. PLoS ONE 6:e19019. doi: 10.1371/journal.pone.0019019

Nielsen, J. S., Lei, L. K., Ebersbach, T., Olsen, A. S., Klitgaard, J. K., Valentin-Hansen, P., et al. (2010). Defining a role for Hfq in Gram-positive bacteria: evidence for Hfq-dependent antisense regulation in Listeria monocytogenes. Nucleic Acids Res. 38, 907-919. doi: 10.1093/nar/gkp1081
Otaka, H., Ishikawa, H., Morita, T., and Aiba, H. (2011). PolyU tail of rhoindependent terminator of bacterial small RNAs is essential for Hfq action. Proc. Natl. Acad. Sci. U.S.A. 108, 13059-13064. doi: 10.1073/pnas.1107050108

Overgaard, M., Johansen, J., Moller-Jensen, J., and Valentin-Hansen, P. (2009) Switching off small RNA regulation with trap-mRNA. Mol. Microbiol. 73, 790-800. doi: 10.1111/j.1365-2958.2009.06807.x

Pacheco, A. R., Curtis, M. M., Ritchie, J. M., Munera, D., Waldor, M. K., Moreira, C. G., et al. (2012). Fucose sensing regulates bacterial intestinal colonization. Nature 492, 113-117. doi: 10.1038/nature11623

Papenfort, K., Bouvier, M., Mika, F., Sharma, C. M., and Vogel, J. (2010). Evidence for an autonomous $5^{\prime}$ target recognition domain in an Hfqassociated small RNA. Proc. Natl. Acad. Sci. U.S.A. 107, 20435-20440. doi: 10.1073/pnas.1009784107

Papenfort, K., Pfeiffer, V., Lucchini, S., Sonawane, A., Hinton, J. C., and Vogel, J. (2008). Systematic deletion of Salmonella small RNA genes identifies CyaR, a conserved CRP-dependent riboregulator of OmpX synthesis. Mol. Microbiol. 68, 890-906. doi: 10.1111/j.1365-2958.2008.06189.x

Papenfort, K., Pfeiffer, V., Mika, F., Lucchini, S., Hinton, J. C., and Vogel, J. (2006). SigmaE-dependent small RNAs of Salmonella respond to membrane stress by accelerating global omp mRNA decay. Mol. Microbiol. 62, 1674-1688. doi: 10.1111/j.1365-2958.2006.05524.x

Papenfort, K., Podkaminski, D., Hinton, J. C., and Vogel, J. (2012). The ancestral SgrS RNA discriminates horizontally acquired Salmonella mRNAs through a single G-U wobble pair. Proc. Natl. Acad. Sci. U.S.A. 109, E757-E764. doi: 10.1073/pnas.1119414109

Papenfort, K., Sun, Y., Miyakoshi, M., Vanderpool, C. K., and Vogel, J. (2013). Small RNA-mediated activation of sugar phosphatase mRNA regulates glucose homeostasis. Cell 153, 426-437. doi: 10.1016/j.cell.2013.03.003

Papenfort, K., and Vogel, J. (2010). Regulatory RNA in bacterial pathogens. Cell Host Microbe 8, 116-127. doi: 10.1016/j.chom.2010.06.008

Papenfort, K., and Vogel, J. (2011). Sweet business: Spot42 RNA networks with CRP to modulate catabolite repression. Mol. Cell 41, 245-246. doi: 10.1016/j.molcel.2011.01.011

Petersen, S., and Young, G. M. (2002). Essential role for cyclic AMP and its receptor protein in Yersinia enterocolitica virulence. Infect. Immun. 70, 3665-3672. doi: 10.1128/IAI.70.7.3665-3672.2002

Plumbridge, J., Bossi, L., Oberto, J., Wade, J. T., and Figueroa-Bossi, N. (2014). Interplay of transcriptional and small RNA-dependent control mechanisms regulates chitosugar uptake in Escherichia coli and Salmonella. Mol. Microbiol. 92, 648-658. doi: $10.1111 / \mathrm{mmi} .12573$

Plumbridge, J., and Pellegrini, O. (2004). Expression of the chitobiose operon of Escherichia coli is regulated by three transcription factors: NagC, ChbR and CAP. Mol. Microbiol. 52, 437-449. doi: 10.1111/j.1365-2958.2004.03986.x

Polayes, D. A., Rice, P. W., Garner, M. M., and Dahlberg, J. E. (1988). Cyclic AMPcyclic AMP receptor protein as a repressor of transcription of the spf gene of Escherichia coli. J. Bacteriol. 170, 3110-3114.

Poncet, S., Milohanic, E., Maze, A., Nait Abdallah, J., Ake, F., Larribe, M., et al. (2009). Correlations between carbon metabolism and virulence in bacteria. Contrib. Microbiol. 16, 88-102. doi: 10.1159/000219374

Rasmussen, A. A., Johansen, J., Nielsen, J. S., Overgaard, M., Kallipolitis, B., and Valentin-Hansen, P. (2009). A conserved small RNA promotes silencing of the outer membrane protein YbfM. Mol. Microbiol. 72, 566-577. doi: 10.1111/j.1365-2958.2009.06688.x

Reading, N. C., Torres, A. G., Kendall, M. M., Hughes, D. T., Yamamoto, K., and Sperandio, V. (2007). A novel two-component signaling system that activates transcription of an enterohemorrhagic Escherichia coli effector involved in remodeling of host actin. J. Bacteriol. 189, 2468-2476. doi: 10.1128/JB.01848-06

Reichenbach, B., Gopel, Y., and Gorke, B. (2009). Dual control by perfectly overlapping sigma 54- and sigma 70- promoters adjusts small RNA GlmY expression to different environmental signals. Mol. Microbiol. 74, 1054-1070. doi: 10.1111/j.1365-2958.2009.06918.x

Reichenbach, B., Maes, A., Kalamorz, F., Hajnsdorf, E., and Gorke, B. (2008). The small RNA GlmY acts upstream of the sRNA GlmZ in the activation of glmS expression and is subject to regulation by polyadenylation in Escherichia coli. Nucleic Acids Res. 36, 2570-2580. doi: 10.1093/nar/gkn091

Rice, J. B., Balasubramanian, D., and Vanderpool, C. K. (2012). Small RNA binding-site multiplicity involved in translational regulation of a polycistronic mRNA. Proc. Natl. Acad. Sci. U.S.A. 109, E2691-E2698. doi: 10.1073/pnas. 12079 27109 
Rice, J. B., and Vanderpool, C. K. (2011). The small RNA SgrS controls sugarphosphate accumulation by regulating multiple PTS genes. Nucleic Acids Res. 39, 3806-3819. doi: 10.1093/nar/gkq1219

Rice, P. W., and Dahlberg, J. E. (1982). A gene between polA and glnA retards growth of Escherichia coli when present in multiple copies: physiological effects of the gene for spot 42 RNA. J. Bacteriol. 152, 1196-1210.

Richard, A. L., Withey, J. H., Beyhan, S., Yildiz, F., and Dirita, V. J. (2010). The Vibrio cholerae virulence regulatory cascade controls glucose uptake through activation of TarA, a small regulatory RNA. Mol. Microbiol. 78, 1171-1181. doi: 10.1111/j.1365-2958.2010.07397.x

Richards, G. R., Patel, M. V., Lloyd, C. R., and Vanderpool, C. K. (2013). Depletion of glycolytic intermediates plays a key role in glucose-phosphate stress in Escherichia coli. J. Bacteriol. 195, 4816-4825. doi: 10.1128/JB. 00705-13

Richards, G. R., and Vanderpool, C. K. (2012). Induction of the Pho regulon suppresses the growth defect of an Escherichia coli sgrS mutant, connecting phosphate metabolism to the glucose-phosphate stress response. J. Bacteriol. 194, 2520-2530. doi: 10.1128/JB.00009-12

Richards, G. R., Vivas, E. I., Andersen, A. W., Rivera-Santos, D., Gilmore, S., Suen, G., et al. (2009). Isolation and characterization of Xenorhabdus nematophila transposon insertion mutants defective in lipase activity against Tween. J. Bacteriol. 191, 5325-5331. doi: 10.1128/JB.00 173-09

Romeo, T., Gong, M., Liu, M. Y., and Brun-Zinkernagel, A. M. (1993). Identification and molecular characterization of csrA, a pleiotropic gene from Escherichia coli that affects glycogen biosynthesis, gluconeogenesis, cell size, and surface properties. J. Bacteriol. 175, 4744-4755.

Romeo, T., Vakulskas, C. A., and Babitzke, P. (2013). Post-transcriptional regulation on a global scale: form and function of Csr/Rsm systems. Environ. Microbiol. 15, 313-324. doi: 10.1111/j.1462-2920.2012.02794.x

Santiviago, C. A., Reynolds, M. M., Porwollik, S., Choi, S. H., Long, F., AndrewsPolymenis, H. L., et al. (2009). Analysis of pools of targeted Salmonella deletion mutants identifies novel genes affecting fitness during competitive infection in mice. PLoS Pathog. 5:e1000477. doi: 10.1371/journal.ppat.10 00477

Serganov, A., and Nudler, E. (2013). A decade of riboswitches. Cell 152, 17-24. doi: 10.1016/j.cell.2012.12.024

Seyll, E., and Van Melderen, L. (2013). The ribonucleoprotein csr network. Int. J. Mol. Sci. 14, 22117-22131. doi: 10.3390/ijms141122117

Shao, Y., Feng, L., Rutherford, S. T., Papenfort, K., and Bassler, B. L. (2013). Functional determinants of the quorum-sensing non-coding RNAs and their roles in target regulation. EMBO J. 32, 2158-2171. doi: 10.1038/emboj. 2013.155

Sharma, C. M., Hoffmann, S., Darfeuille, F., Reignier, J., Findeiss, S., Sittka, A., et al. (2010). The primary transcriptome of the major human pathogen Helicobacter pylori. Nature 464, 250-255. doi: 10.1038/nature08756

Sharma, C. M., Papenfort, K., Pernitzsch, S. R., Mollenkopf, H. J., Hinton, J. C., and Vogel, J. (2011). Pervasive post-transcriptional control of genes involved in amino acid metabolism by the Hfq-dependent GcvB small RNA. Mol. Microbiol. 81, 1144-1165. doi: 10.1111/j.1365-2958.2011.07751.x

Skorupski, K., and Taylor, R. K. (1997). Cyclic AMP and its receptor protein negatively regulate the coordinate expression of cholera toxin and toxincoregulated pilus in Vibrio cholerae. Proc. Natl. Acad. Sci. U.S.A. 94, 265-270. doi: 10.1073/pnas.94.1.265

Sobrero, P., and Valverde, C. (2012). The bacterial protein Hfq: much more than a mere RNA-binding factor. Crit. Rev. Microbiol. 38, 276-299. doi: 10.3109/1040841X.2012.664540

Song, T., Mika, F., Lindmark, B., Liu, Z., Schild, S., Bishop, A., et al. (2008). A new Vibrio cholerae sRNA modulates colonization and affects release of outer membrane vesicles. Mol. Microbiol. 70, 100-111. doi: 10.1111/j.13652958.2008.06392.x

Soutourina, O. A., Monot, M., Boudry, P., Saujet, L., Pichon, C., Sismeiro, O., et al. (2013). Genome-wide identification of regulatory RNAs in the human pathogen Clostridium difficile. PLoS Genet. 9:e1003493. doi: 10.1371/journal.pgen.1003493

Sterzenbach, T., Nguyen, K. T., Nuccio, S. P., Winter, M. G., Vakulskas, C. A., Clegg, S., et al. (2013). A novel CsrA titration mechanism regulates fimbrial gene expression in Salmonella typhimurium. EMBO J. 32, 2872-2883. doi: 10.1038/emboj.2013.206
Sun, Y., and Vanderpool, C. K. (2013). Physiological consequences of multipletarget regulation by the small RNA SgrS in Escherichia coli. J. Bacteriol. 195, 4804-4815. doi: 10.1128/JB.00722-13

Suzuki, K., Babitzke, P., Kushner, S. R., and Romeo, T. (2006). Identification of a novel regulatory protein $(\mathrm{CsrD})$ that targets the global regulatory RNAs CsrB and CsrC for degradation by RNase E. Genes Dev. 20, 2605-2617. doi: 10.1101/gad.1461606

Suzuki, K., Wang, X., Weilbacher, T., Pernestig, A. K., Melefors, O., Georgellis, D., et al. (2002). Regulatory circuitry of the CsrA/CsrB and BarA/UvrY systems of Escherichia coli. J. Bacteriol. 184, 5130-5140. doi: 10.1128/JB.184.18.51305140.2002

Teplitski, M., Goodier, R. I., and Ahmer, B. M. (2006). Catabolite repression of the SirA regulatory cascade in Salmonella enterica. Int. J. Med. Microbiol. 296, 449-466. doi: 10.1016/j.ijmm.2006.06.001

Thomason, M. K., Fontaine, F., De Lay, N., and Storz, G. (2012). A small RNA that regulates motility and biofilm formation in response to changes in nutrient availability in Escherichia coli. Mol. Microbiol. 84, 17-35. doi: 10.1111/j.13652958.2012.07965.x

Urban, J. H., Papenfort, K., Thomsen, J., Schmitz, R. A., and Vogel, J. (2007). A conserved small RNA promotes discoordinate expression of the glmUS operon mRNA to activate GlmS synthesis. J. Mol. Biol. 373, 521-528. doi: 10.1016/j.jmb.2007.07.035

Urban, J. H., and Vogel, J. (2008). Two seemingly homologous noncoding RNAs act hierarchically to activate glmS mRNA translation. PLoS Biol. 6:e64. doi: 10.1371/journal.pbio.0060064

Vanderpool, C. K., and Gottesman, S. (2004). Involvement of a novel transcriptional activator and small RNA in post-transcriptional regulation of the glucose phosphoenolpyruvate phosphotransferase system. Mol. Microbiol. 54, 1076-1089. doi: 10.1111/j.1365-2958.2004.04348.x

Vanderpool, C. K., and Gottesman, S. (2007). The novel transcription factor SgrR coordinates the response to glucose-phosphate stress. J. Bacteriol. 189, 2238-2248. doi: 10.1128/JB.01689-06

Van Opijnen, T., and Camilli, A. (2013). Transposon insertion sequencing: a new tool for systems-level analysis of microorganisms. Nat. Rev. Microbiol. 11, 435-442. doi: 10.1038/nrmicro3033

Vogel, J., Bartels, V., Tang, T. H., Churakov, G., Slagter-Jager, J. G., Huttenhofer, A., et al. (2003). RNomics in Escherichia coli detects new sRNA species and indicates parallel transcriptional output in bacteria. Nucleic Acids Res. 31, 6435-6443. doi: $10.1093 / \mathrm{nar} / \mathrm{gkg} 867$

Vogel, J., and Luisi, B. F. (2011). Hfq and its constellation of RNA. Nat. Rev. Microbiol. 9, 578-589. doi: 10.1038/nrmicro2615

Wadler, C. S., and Vanderpool, C. K. (2007). A dual function for a bacterial small RNA: SgrS performs base pairing-dependent regulation and encodes a functional polypeptide. Proc. Natl. Acad. Sci. U.S.A. 104, 20454-20459. doi: 10.1073/pnas.0708102104

Wang, X., Dubey, A. K., Suzuki, K., Baker, C. S., Babitzke, P., and Romeo, T. (2005). CsrA post-transcriptionally represses pgaABCD, responsible for synthesis of a biofilm polysaccharide adhesin of Escherichia coli. Mol. Microbiol. 56, 1648-1663. doi: 10.1111/j.1365-2958.2005.04648.x

Waters, L. S., and Storz, G. (2009). Regulatory RNAs in bacteria. Cell 136, 615-628. doi: 10.1016/j.cell.2009.01.043

Westermann, A. J., Gorski, S. A., and Vogel, J. (2012). Dual RNA-seq of pathogen and host. Nat. Rev. Microbiol. 10, 618-630. doi: 10.1038/nrmicro2852

Wright, P. R., Richter, A. S., Papenfort, K., Mann, M., Vogel, J., Hess, W. R., et al. (2013). Comparative genomics boosts target prediction for bacterial small RNAs. Proc. Natl. Acad. Sci. U.S.A. 110, E3487-E3496. doi: 10.1073/pnas.1303248110

Xiong, X., Frank, D. N., Robertson, C. E., Hung, S. S., Markle, J., Canty, A J., et al. (2012). Generation and analysis of a mouse intestinal metatranscriptome through Illumina based RNA-sequencing. PLoS ONE 7:e36009. doi: 10.1371/journal.pone.0036009

Yakhnin, A. V., Baker, C. S., Vakulskas, C. A., Yakhnin, H., Berezin, I., Romeo, T., et al. (2013). CsrA activates flhDC expression by protecting flhDC mRNA from RNase E-mediated cleavage. Mol. Microbiol. 87, 851-866. doi: $10.1111 / \mathrm{mmi} .12136$

Yamamoto, S., Izumiya, H., Mitobe, J., Morita, M., Arakawa, E., Ohnishi, M., et al. (2011). Identification of a chitin-induced small RNA that regulates translation of the tfoX gene, encoding a positive regulator of natural competence in Vibrio cholerae. J. Bacteriol. 193, 1953-1965. doi: 10.1128/JB.01340-10 
Yan, Y., Su, S., Meng, X., Ji, X., Qu, Y., Liu, Z., et al. (2013). Determination of sRNA expressions by RNA-seq in Yersinia pestis grown in vitro and during infection. PLoS ONE 8:e74495. doi: 10.1371/journal.pone.0074495

Zhang, A., Wassarman, K. M., Rosenow, C., Tjaden, B. C., Storz, G., and Gottesman, S. (2003). Global analysis of small RNA and mRNA targets of Hfq. Mol. Microbiol. 50, 1111-1124. doi: 10.1046/j.1365-2958.2003.03734.x

Zhao, X., Koestler, B. J., Waters, C. M., and Hammer, B. K. (2013). Posttranscriptional activation of a diguanylate cyclase by quorum sensing small RNAs promotes biofilm formation in Vibrio cholerae. Mol. Microbiol. 89, 989-1002. doi: 10.1111/mmi.12325

Conflict of Interest Statement: The Guest Associate Editor Thomas Dandekar declares that, despite being affiliated to the same institution as author Jörg Vogel, the review process was handled objectively and no conflict of interest exists. The authors declare that the research was conducted in the absence of any commercial or financial relationships that could be construed as a potential conflict of interest.

Received: 22 April 2014; accepted: 19 June 2014; published online: 15 July 2014.

Citation: Papenfort K and Vogel J (2014) Small RNA functions in carbon metabolism and virulence of enteric pathogens. Front. Cell. Infect. Microbiol. 4:91. doi: 10.3389/ fimb.2014.00091

This article was submitted to the journal Frontiers in Cellular and Infection Microbiology.

Copyright (c) 2014 Papenfort and Vogel. This is an open-access article distributed under the terms of the Creative Commons Attribution License (CC BY). The use, distribution or reproduction in other forums is permitted, provided the original author(s) or licensor are credited and that the original publication in this journal is cited, in accordance with accepted academic practice. No use, distribution or reproduction is permitted which does not comply with these terms. 